\title{
Role of Red Cell Distribution Width and Mentzer Index in Differentiating Iron Deficiency Anemia from Anemia Due to $\beta$ Thalassemia Trait
}

\author{
Majida Zafar ${ }^{1}$, Arfa Tabassum², Quratulain A Cheema ${ }^{3}$, Syeda B Mazhar ${ }^{4}$
}

\begin{abstract}
Objective: To determine the role of red cell distribution width (RDW) and Mentzer index in differentiating between iron deficiency anemia (IDA) and anemia secondary to $\beta$-thalassemia trait.

Materials and methods: Study design: cross-sectional study.

Setting: Department of Obstetrics and Gynecology, MCH Unit I, PIMS, Islamabad.

Duration: Six months. Primigravida with hemoglobin less than $10 \mathrm{mg} / \mathrm{dL}$ was selected. All patients were investigated with serum ferritin and $\mathrm{Hb}$ electrophoresis for confirmation of the thalassemia trait. Primary outcome measures were the significance of RDW and Mentzer index in differentiating IDA from anemia secondary to $\beta$-thalassemia trait. Secondary outcome measures were the prevalence of IDA and $\beta$-thalassemia trait in primigravida women.

Results: Out of the total 178 women with microcytic hypochromic anemia, 164 (92.1\%) had IDA, $9(5.1 \%)$ had coexistent IDA and $\beta$-thalassemia trait, and 5 (2.8\%) had $\beta$-thalassemia trait alone. The mean RDW was $20.6 \pm 5.8$ in IDA category, $16.4 \pm 6.7$ in IDA + $\beta$-thalassemia trait, and 14.1 \pm 6.5 in $\beta$-thalassemia trait alone category. RDW was significantly higher in IDA category ( $p$ value $=0.01$ ). Similarly, the mean Mentzer index was 21.0 in IDA, 16.1 in IDA + $\beta$-thalassemia trait category. However, it was significantly low 12.2 in $\beta$-thalassemia trait alone category ( $p$ value $\leq 0.001)$. Conclusion: The RDW and Mentzer index have useful significance in differentiating $\beta$-thalassemia trait and IDA, it can be used as a primary tool in low resource settings.

Keywords: Anemia, $\beta$ thalassemia trait, Mentzer index, Red cell distribution width.

Journal of South Asian Federation of Obstetrics and Gynaecology (2019): 10.5005/jp-journals-10006-1718
\end{abstract}

\section{INTRODUCTION}

Anemia is a disorder with hemoglobin levels lower than normal or when total red blood cells are lesser than the average value.' Iron deficiency anemia (IDA) is the most common cause of anemia worldwide. $^{2}$ In Pakistan, the prevalence of IDA is $70-80 \%$ among the pregnant population. ${ }^{3}$

The loss of iron in normal pregnancy, delivery, and lactation tends to put women towards negative iron balance. ${ }^{4}$ Serum ferritin is the most sensitive laboratory investigation to differentiate IDA from anemia due to other disorders.

$\beta$-thalassemia trait (BTT) is documented as the most common single-gene disorder transmitted by heredity. ${ }^{5}$

Pakistan lies in the thalassemia belt, where about 3-8\% of the total population has BTT. ${ }^{6}$ It is asymptomatic and commonly discovered during periods of stress, such as pregnancy. 3,6

The subjects of $\beta$-thalassemia usually have normal iron stores and a microcytic hypochromic blood picture. Unfortunately, they are often erroneously treated with iron. Administration of iron to these cases can actually be harmful and produce complications of iron overload. ${ }^{6} \mathrm{Hb}$ electrophoresis with elevated $\mathrm{HbA} 2$ level is the gold standard for thalassemia screening. ${ }^{3}$

Iron deficiency is coexisting with BTT among individuals with lower hemoglobin levels. ${ }^{7,8}$ Saraya et al. explained that iron deficiency in BTT leads to a lack of hemopoietic nutrients in addition to an imbalance in globin chain synthesis resulting in a further reduction in hemoglobin production. ${ }^{9}$ \begin{tabular}{l}
\hline \hline 1-4Maternal and Child Health Care Centre, Pakistan Institute of Medical \\
Science, Islamabad, Pakistan \\
Corresponding Author: Majida Zafar, Maternal and Child Health Care \\
Centre, Pakistan Institute of Medical Science, Islamabad, Pakistan, \\
Phone: +03335252295, e-mail: majidazafar82@yahoo.com \\
How to cite this article: Zafar M, Tabassum A, Cheema QA, et al. Role of \\
Red Cell Distribution Width and Mentzer Index in Differentiating Iron \\
Deficiency Anemia from Anemia Due to $\beta$ Thalassemia Trait. J South \\
Asian Feder Obst Gynae 2019;11(5):297-300. \\
Source of support: Nil \\
Conflict of interest: None \\
\hline \hline
\end{tabular}

The reduction in $\mathrm{HbA}_{2}$ levels in patients with concomitant BTT and IDA has been suggested to interfere in the diagnosis of the former. There is a lack of trials that have associated the prevalence of IDA, BTT, and coexistence of both in a primigravida with hemoglobin less than $10 \mathrm{~g} / \mathrm{dL} .{ }^{10,11}$

There are concerns regarding the differentiation of IDA and BTT. $\mathrm{Hb}$ electrophoresis though the gold standard is an expensive test. A study was therefore undertaken to assess red cell distribution width (RDW) and Mentzer index (MI) as an indicator for differentiating between these two types of anemia.

The current study was carried out to determine the prevalence of thalassemia trait in patients with IDA in primigravida women presenting with microcytic hypochromic anemia to the Maternal and Child Health Care (MCH) centre, Pakistan Institute of Medical Sciences, Islamabad, Pakistan.

(อ) The Author(s). 2019 Open Access This article is distributed under the terms of the Creative Commons Attribution 4.0 International License (https://creativecommons. org/licenses/by-nc/4.0/), which permits unrestricted use, distribution, and non-commercial reproduction in any medium, provided you give appropriate credit to the original author(s) and the source, provide a link to the Creative Commons license, and indicate if changes were made. The Creative Commons Public Domain Dedication waiver (http://creativecommons.org/publicdomain/zero/1.0/) applies to the data made available in this article, unless otherwise stated. 


\section{Materials and Methods}

\section{Setting and Study Design}

In this cross-sectional study, all eligible pregnant women fulfilling inclusion criteria who attended antenatal clinics at the MCH centre Unit 1, Pakistan Institute of Medical Sciences (PIMS), Islamabad from June 2015 to December 2015 were enrolled. The study was approved by the Ethical Review Committee of PIMS. The laboratory services were provided with the collaboration of pathology department of Shaheed Zulfiqar Ali Bhutto Medical University (SZABMU), PIMS, Islamabad.

\section{Sample Size}

The sample size has been calculated by using the WHO calculator with the statistical assumptions of $90 \%$ power and $10 \%$ alpha error of study and magnitude of IDA $79 \%$. A total of 178 patients were enrolled in this study through non-probability consecutive sampling technique.

\section{Inclusion and Exclusion Criteria}

All primigravida, with a singleton pregnancy, between 18 years and 49 years of age with $\mathrm{Hb}$ less than $10 \mathrm{~g} / \mathrm{dL}$ and microcytic hypochromic anemia were enrolled in this study. Multigravida, multiple gestations, and pregnant women with $\mathrm{Hb}$ more than $10 \mathrm{~g} / \mathrm{dL}$ were excluded from the study. Women who received blood transfusion in the last 4 weeks were also excluded from the study.

\section{Data Collection and Analysis}

Pregnant women fulfilling inclusion criteria were registered through Obstetrics and Gynecology Out Patient Department of MCH-1 PIMS, Islamabad. Demographic history including age (years), residence, occupation, family history of BTT, and family history of transfusions during pregnancy were taken. All the patients were investigated with serum ferritin and $\mathrm{Hb}$ electrophoresis. The blood was drawn by a trained phlebotomist. Women were followed-up after 1 week to document and save the results. All the information was collected on a specially designed pro forma. To minimize selection bias and maintain data quality of all study procedures, the data collection was performed by the researcher herself. Informed consent was taken from patients or caretakers.

The collected data was entered into SPSS version 11 and analyzed. The qualitative data like the presence of IDA (yes or no) and BTT (yes or no), occupation, residence, family history of BTT, and family history of transfusions during pregnancy were presented as frequency distribution.

Quantitative data like age and gestational age were presented as means and standard deviations. Chi-square test was applied to compare the frequency of BTT with IDA. A $p$ value of $<0.05$ was considered statistically significant.

Red cell distribution width and $\mathrm{MI}$ was calculated from the report of blood complete picture, and the sensitivity of RDW and MI was calculated as compared to serum ferritin and $\mathrm{Hb}$ electrophoresis for differentiating between IDA and anemia due to BTT.

\section{Outcome Measures}

Primary outcome measures were the significance of RDW and MI in differentiating IDA from anemia secondary to BTT. Secondary outcome measures were the prevalence of IDA and BTT in primigravida women.

\section{Operational Definitions}

\section{Anemia}

Hemoglobin of less than $10.0 \mathrm{~g} / \mathrm{dL}$ at any time during pregnancy in developing countries, according to $\mathrm{WHO}^{2}$

\section{Red Cell Distribution Width}

The measure of the range of variation in the volume of RBC reported as a part of the standard complete blood count (CBC) is RDW. Mathematically, the red cell distribution width is calculated as (standard deviation of $\mathrm{MCV} /$ mean $\mathrm{MCV}$ ) $\times 100$. The normal range of RDW (11.5-14.5\%) has a high suspicion of thalassemia trait, and high RDW often indicates IDA. ${ }^{12,13}$

\section{Mentzer Index}

The Mentzer index was first described by Mentzer in the year 1973. It is calculated from the CBC report. Mentzer index (MCV/RBC count) of less than 13 may represent thalassemia trait, and greater than 13 often indicates IDA. ${ }^{13}$

\section{Results}

Out of the total 178 primigravida women, with hypochromic microcytic anemia 164 (92.1\%) had IDA, 9 (5.1\%) had IDA with coexistent BTT, and 5 (2.8\%) had BTT alone (Fig. 1).

The mean age of study patients was $25.1+3.9$ years. More than $80.0 \%$ of the patients were between 21 years and 30 years of age. The mean gestational age of the patients at the time of assessment of IDA was $30.4+3.8$ weeks. More than $90.0 \%$ had a gestational age between 26 weeks and 37 weeks. Majority 164 (92.1\%) were living in the urban area, and most of the women were housewives 168 (94.3\%). Nine (5.1\%) patients had a positive family history of BTT. Similarly, 21 (11.8\%) women were found to have a positive family history of transfusion during pregnancy.

It was found that BTT was more common among pregnant women of younger than 25 years of age $(n=10)$ compared to older women $(n=4)$, and those having a family history of BTT. Secondarily, women having a positive family history of blood transfusion during pregnancy were significantly more likely to have $\beta$-thalassemia in the present study ( $p$ value $\leq 0.001$ ) (Table 1$)$.

The mean hemoglobin was $8.79+0.60 \mathrm{mg} / \mathrm{dL}$ in the study patients. The mean RBC count was found to be $3.63+0.83$ million $/ \mu \mathrm{L}$.

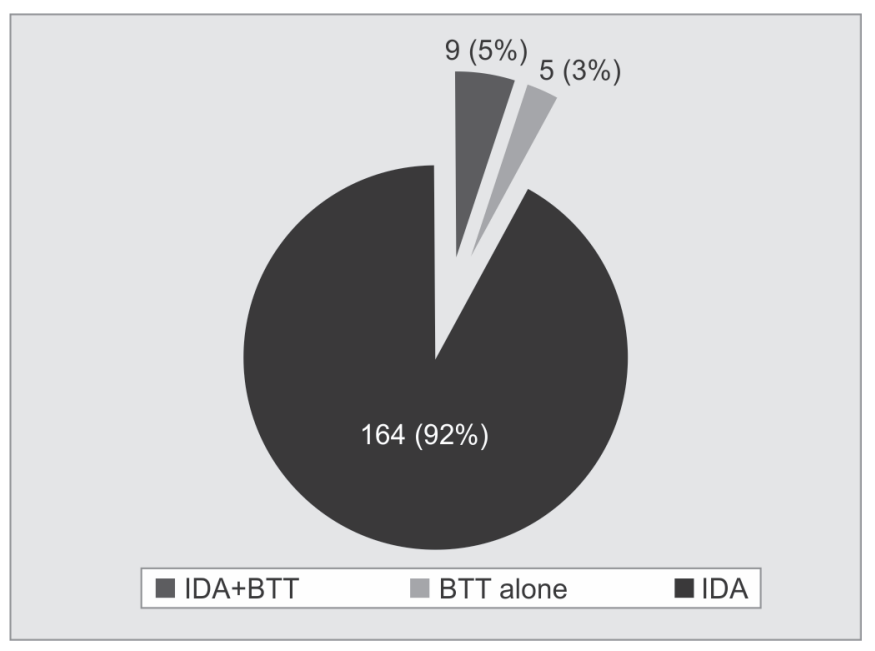

Fig. 1: Iron deficiency anemia with coexistent $\beta$-thalassemia trait $(n=178)$ 
Table 1: Factors associated with $\beta$-thalassemia trait $(n=178)$

\begin{tabular}{lccc}
\hline & $\begin{array}{c}\text { Total cases of } \\
\beta \text {-thalassemia }(n=14)\end{array}$ & IDA $(n=164)$ & $p$ value \\
\hline Age (years) & & & \\
Up to 20 & $1(7.1 \%)$ & $25(15.2 \%)$ & 0.02 \\
$21-25$ & $9(64.0 \%)$ & $56(34.1 \%)$ & \\
$26-30$ & $3(21.3 \%)$ & $76(46.3 \%)$ & \\
31 or above & $1(7.1 \%)$ & $7(4.2 \%)$ & \\
Family h/o $\beta$ thalassemia & & \\
Yes & $5(35.7 \%)$ & $4(2.4 \%)$ & $<0.001$ \\
No & $9(64.2 \%)$ & $160(97.6 \%)$ & \\
Family h/o transfusion in pregnancy & & \\
Yes & $6(42.8 \%)$ & $15(9.1 \%)$ & $<0.001$ \\
No & $8(57.2 \%)$ & $149(90.9 \%)$ & \\
\hline \multicolumn{4}{c}{}
\end{tabular}

Table 2: Average red cell distribution width and Mentzer index values in IDA and $\beta$-thalassemia categories

\begin{tabular}{|c|c|c|c|c|}
\hline & IDA $(n=164)$ & $\begin{array}{l}\beta \text { thalassemia } \\
\text { trait and } \\
\text { coexistent IDA } \\
(n=9)\end{array}$ & $\begin{array}{l}\beta \text { thalassemia } \\
\text { trait alone } \\
(n=5)\end{array}$ & $p$ value \\
\hline RDW & $20.6 \pm 5.8$ & $16.4 \pm 6.7$ & $14.1 \pm 6.5$ & 0.01 \\
\hline $\begin{array}{l}\text { Mentzer } \\
\text { index }\end{array}$ & $21.0 \pm 10.5$ & $16.1 \pm 6.2$ & $12.2 \pm 5.3$ & $<0.001$ \\
\hline
\end{tabular}

Table 3: Sensitivity and specificity of red cell distribution width and Mentzer index in diagnosis of iron deficiency anemia keeping serum ferritin as diagnostic standard $(n=178)$

\begin{tabular}{lll}
\hline Diagnostic parameters & RDW (\%) & Mentzer index (\%) \\
\hline Sensitivity & 94.2 & 99.4 \\
Specificity & 50.0 & 00.0 \\
Positive predictive value & 98.8 & 97.7 \\
Positive predictive value & 16.6 & 00.0 \\
\hline
\end{tabular}

The mean MCV was $68.28+8.54 \mathrm{fL}, \mathrm{MCH}$ was $23.31+15.14 \mathrm{pg}$, and $\mathrm{MCHC}$ was $26.91+5.35 \mathrm{mg} / \mathrm{dL}$.

The average RDW and $\mathrm{MI}$ in different categories, i.e., IDA, coexistent BTT, and IDA and BTT, alone were calculated. The mean RDW was 18.7 in IDA category, 16.4 in IDA + BTT, and 14.7 in BTT alone ( $p$ value $=0.01$ ). Similarly, the mean MI was 21.0 in IDA, 16.1 in IDA + BTT category, however, it was significantly low 12.2 in BTT alone category ( $p$ value $=<0.001$ ) (Table 2 ).

The sensitivity and specificity of RDW and MI were calculated for the diagnosis of IDA, keeping ferritin level as a diagnostic standard. The sensitivity and specificity of RDW in diagnosing IDA keeping ferritin as standard was $94.2 \%$ and $50.0 \%$, respectively. The positive predictive value (PPV) and negative predictive value (NPV) were $98.8 \%$ and $16.6 \%$. The sensitivity and specificity of $\mathrm{Ml}$ in diagnosing IDA were found to be $99.4 \%$ and $00.0 \%$, respectively (Table 3 ).

When $\mathrm{Hb}$ electrophoresis was kept gold standard for diagnosis of BTT, the sensitivity, and specificity of RDW, were found to be $64.2 \%$ and $98.1 \%$, respectively. The PPV and NPV were found to be $75.0 \%$ and $96.9 \%$, respectively. Moreover, the sensitivity and specificity of Ml in the diagnosis of BTT keeping $\mathrm{Hb}$ electrophoresis as gold standard was found to be $7.1 \%$ and $100 \%$, respectively. Similarly, the PPV and NPV of MI were found to be $100 \%$ and $92.6 \%$, respectively (Table 4).
Table 4: Sensitivity and specificity of red cell distribution width (RDW) and Mentzer index in diagnosis of $\beta$-thalassemia trait keeping $\mathrm{Hb}$ electrophoresis as gold standard $(n=178)$

\begin{tabular}{llc}
\hline $\begin{array}{l}\text { Diagnostic } \\
\text { parameters }\end{array}$ & $R D W(\%)$ & Mentzer index (\%) \\
\hline Sensitivity & 64.2 & 7.1 \\
Specificity & 98.1 & 100 \\
Positive predictive value & 75.0 & 100 \\
Negative predictive value & 96.9 & 92.6 \\
\hline
\end{tabular}

\section{Discussion}

The results of our study show that IDA was present in $92 \%$ of primigravida pregnant women whereas it was $78 \%$ in a national study by Toheed et al. ${ }^{14}$ while it was $41 \%$ in a Turkish study conducted by Taner et al. ${ }^{15}$ Study by Al-Shammari showed, by taking into account the measurement of serum iron, serum ferritin, and total iron-binding capacity, that $79 \%$ anemic pregnant women had iron deficiency. $\mathrm{Hb}$ electrophoresis showed an elevated $\mathrm{HbA} 2$ level in only $2 \%$ of cases. ${ }^{3}$ Another study by Dolai et al. concluded that IDA is a coexisting condition in BTT. $^{4}$

In our study, the average age of patients was 25 years, with majority between 21 years and 30 years. A slightly greater mean age of 30 years of presentation of women was reported by Chang et al. ${ }^{16}$ Dolai from India witnessed a mean age of women presenting with IDA of 30 years. ${ }^{4}$ Ahmed reported from UAE that majority of their cases having mild anemia were up to 30 years of age. ${ }^{17}$ Younger age in our study could be due to the selection of primigravida women only.

The average gestational age of women was $30.4+3.8$ weeks (third trimester) when the iron deficiency was investigated. In the study by Farzana et al., more than $75 \%$ of their women were in the $2 \mathrm{nd}$ and $3 \mathrm{rd}$ trimester when investigated for IDA. ${ }^{16}$ Nutritional demands of fetuses increase many-fold by the third trimester, thus resulting in iron deficiency during this period in pregnant women.

In our study, the mean hemoglobin level was $8.79 \mathrm{~g} / \mathrm{dL}$ and MCHC was $26.9 \mathrm{~g} / \mathrm{dL}$. In the study by Farzana, the mean values among subjects were hemoglobin $10.7 \mathrm{~g} / \mathrm{dL}$ and MCHC $29.8 \mathrm{~g} / \mathrm{dL}$, shown in cases of $\beta$-thalassemia trait which was coexistent with IDA in pregnancy. ${ }^{16}$

Dolai et al. also witnessed a similar picture of results of blood assessments of their patients with IDA. ${ }^{4}$ These findings were found comparable with our study results, where we also witnessed diminished parameters of blood in our patients of IDA.

In our study, the prevalence of coexistent IDA and BTT in pregnant women presenting with microcytic hypochromic anemia was (5.1\%) out of the total of 178 patients. Moreover, (2.8\%) patients had BTT alone. It was noticed that women with a positive family history of $\beta$-thalassemia (35.7\%) and those having a family history of blood transfusions during pregnancy $(42.8 \%)$ were likely to have positive BTT.

Farzana witnessed a similar proportion of BTT $(6.5 \%)$ in their study women who also presented with pregnancy in Benazirabad of Sindh province. None of their patients had a family history of $\beta$-thalassemia, and there was no history of blood transfusions. ${ }^{16}$

Colah from India screened women, presenting for the first antenatal check-up over a period of 7 years evaluation and screened 
61,935 women, they found out $1.6 \%$ of women having $\beta$-thalassemia heterozygotes. ${ }^{18}$ This is lower than in Pakistani studies.

Sukrat reported a prevalence of $6 \%$ of IDA in their study and confirmed (2.3\%) cases of BTT in their study women from Nakhon Sawan Thailand. ${ }^{19}$

These reports are continuous with our study findings regarding the prevalence of BTT in pregnant women having IDA. There have been many reports regarding BTTs in pregnancy. A previous World Health Organization report revealed that about $7 \%$ of pregnant women were a carrier of $\mathrm{BTT}^{20}$

Study conducted by Ou et al. ${ }^{21}$ and Shrivastav et al. ${ }^{22}$ detected elevated hemoglobin A2 as a marker of BTT in pregnancy.

In our study, on sub-analysis of complete blood count parameters, MI and RDW were found lower in patients with BTT alone. However, they were found raised in IDA cases. These findings of RDW and $\mathrm{MI}$ are continuous with previous study reports and validate the results of previous studies on the topic. ${ }^{12}$ In our study, the RDW cut-off was $<15$ in BTT cases, and the MI cut-off was $<13$ in these cases.

The RDW and MI have useful significance in differentiating BTT and IDA. In the present study, both RDW and MI had high sensitivity and average specificity in the diagnosis of IDA, while an average sensitivity and high specificity in the diagnosis of BTT. Beyan et al. reported the same findings in their study. ${ }^{12}$ The high sensitivity for IDA is beneficial because iron deficiency is a condition not desired to be missed in an iron-deficient population. Advantageously, the study also shows a high specificity of RDW and MI for ruling out BTT that requires expensive test $\mathrm{Hb}$ electrophoresis for diagnosis.

However, Mazza et al. suggest that in practice, MI can not be completely used as an indicator of the type of anemia because in thalassemia RBC count is normal, and MCV is low. Practically, the RBC count has to be extremely high, and the MCV extremely low to achieve an Ml of less than 13. And this is something rare to be seen, raising queries about the reliability of the index. ${ }^{12,13}$

The strengths of this study are that a large sample of primigravida women with microcytic hypochromic anemia was recruited. All had iron store studies as well as $\mathrm{Hb}$ electrophoresis was done, which is a useful data for the population of the federal capital Islamabad. A cheap readily available test complete blood count was utilized to extract the RDW and MI. These were assessed and compared with gold standard for IDA and BTT.

The limitations of this study are that spot enrollment was done using a cross-sectional observational design. Moreover, the patients were not followed up until delivery.

\section{Conclusion}

The coexistence of IDA and BTT in primigravida women is $5.1 \%$ in our study. The RDW and MI have useful significance, in differentiating BTT and IDA, it can be used as a primary tool in low resource settings. They can be used as screening to select patients for $\mathrm{Hb}$ electrophoresis (gold standard) and prevent unnecessary parenteral iron supplementation to the cases of BTT.

This is a baseline study revealing the existence of BTT in IDA among primigravida women with microcytic hypochromic anemia and the role of RDW and MI as less expensive modalities. Further large-scale studies are needed with a rigorous methodology to follow the affected patients and collecting information regarding their long-term outcome.

\section{References}

1. Clark P, Thomson AJ, Greer IA. Hematological problems in pregnancy. In: Edmonds K, ed. Dew Hurst's textbook of Obstetrics and Gynaecology, 8th ed., UK: Wiley-Blackwell; 2012. p. 151.

2. Merrill RD, Shamim AA, Ali $H$, et al. High prevalence on anemia with lack of iron deficiency among women in rural Bangladesh: a role for thalassemia and iron in groundwater. Asian Pac J ClinNutr 2012;21(3):416-424.

3. Al-Shammari HH. Iron deficiency anemia and beta thalassemia trait in anemic pregnant women. Fac Med Baghda 2010;52:282-285.

4. Dolai TK, Nataraj KS, Sinha N, et al. Prevalance of iron deficiency in thalassemia minor: a study from tertiary hospital. Indian J Hematol Blood Transfus 2012;28(1):7-9. DOI: 10.1007/s12288-011-0088-9.

5. Batebi A, Pourezza A, Esmillian R. Discrimination of beta-thalassemia minor and iron deficiency anemia by screening test for red blood cells indices. Turk J Med Sci 2012;42:275-280.

6. Marufur Rahman M, Kirtana K, MahbuburRahman M, et al. Iron status is beta-thalassemia trait in adults. J Dhaka National Med Coll Hos 2011;17:21-24. DOI: 10.3329/jdnmch.v17i2.12211.

7. Alperin JB, Dow PA, Petteway MB. Hemoglobin $\mathrm{A}_{2}$ levels in health and various hematologic disorders. Am J Clin Pathol 1977;67(3):219-226. DOI: 10.1093/ajcp/67.3.219.

8. Qureshi TZ, Anwar M, Ahmed S, et al. Serum ferritin levels in carriers of $\beta$-thalassemia trait. Acta Haematol 1995;94(1):7-9.

9. Saraya AK, Kumar R, Kailash S, et al. Iron deficiency in betaheterozygous thalassemia. Indian J Med Res 1984;79:68-75.

10. Madan N, Beachler L, Kontantinopoulos $P$, et al. Red cell indices and discriminant function in the detection of beta thalassemia train in a population with high prevalence of iron deficiency anemia. Pediatr Cardiol 2010;31:1203-1208. DOI: 10.1007/s00246-010-9799-1.

11. Harrington $A M$, Ward PCJ, Kroft SH. Iron deficiency anemia, betathalassemia minor and anemia of chronic disease. Am J ClinPathol 2008;129(3):466-471.

12. Beyan C, Kaptan K, Ifran A. Predictive value of discrimination indices in differential diagnosis of iron deficiency anemia and beta thalassemia trait. Eur J Haematol 2007;78(6):524-526. DOI: 10.1111/j.1600-0609. 2007.00853.x.

13. Mazza J. Manual of clinical hematology, 3rd ed., Lippincott Williams \& Wilkins; 2002. pp. 152-185.

14. Toheed R, Ayub TB, Ali HS. Prevalence of anemia and its main determinants among primigravidae in antenatal population of a tertiary care hospital of Lahore. P J M H S 2015;9(3):907.

15. Taner CE, Ekin A, Solmaz U, et al. Prevalence and risk factors of anemia among pregnant women attending a high-volume tertiary care center for delivery. J Turk Ger Gynecol Assoc 2015;16(4):231-236. DOI: 10.5152/jtgga.2015.15071.

16. Chang F, Pirzado MS, Qazi RA, et al., The Prevalence and Antenatal Screening of Beta Thalassaemia Trait in Pregnancy by naked Eye Single Tube Red Cell Osmotic Fragility Test. Medical Forum Monthly. Available at URL: www.medicalforum.pk15-09-2014 (Accessed 15-062016).

17. Ahmed A, Nasir $H$, Shafiq $Q$, et al. The effect of anemia on pregnancy and fetal outcome: GMC Hospital, Ajman, UAE. GMJ, ASM 2015;4(S1):S76-S82.

18. Colah R, Surve R, Wadia M, et al. Carrier screening for betathalassemia during pregnancy in India: a 7-year evaluation. Genet Test 2008;12(2):181-185. DOI: 10.1089/gte.2007.0066.

19. Sukrat $B$, Suwathanapisate $P$, Siritawee $S$, et al. The prevalence of iron deficiency anemia in pregnant women in Nakhonsawan, Thailand. J Med Assoc Thai 2010;93(7):765-770.

20. World Health Organization. Facts about prevalence of thalassaemia carrier state in Pregnancy throughout world. WHO Report; 2011.

21. Ou Z, Li Q, Liu W, et al. Elevated hemoglobin A2 as a marker for beta thalassaemia trait in pregnant women. Tohoku J Expl Med 2011;223(3):223-226. DOI: 10.1620/tjem.223.223.

22. Shrivastav A, Patel U, Joshi JR, et al. Thalassaemia and types of beta thalassaemia. J Applied Hematol 2013;4(3):104-109. DOI: 10.4103/1658-5127.123308. 